\title{
Effect of electric heating and ice added to the bowl on mainstream waterpipe semivolatile furan and other toxicant yields
}

\author{
Marielle C Brinkman ㄷ, ${ }^{1}$ Andreas A Teferra, ${ }^{1}$ Noura O Kassem, ${ }^{2}$ Nada OF Kassem ${ }^{2}$
}

- Additional material is published online only. To view please visit the journal online (http://dx.doi.org/10.1136/ tobaccocontrol-2019-054961).

${ }^{1}$ College of Public Health, The Ohio State University, Columbus, Ohio, USA ${ }^{2}$ School of Public Health, San Diego State University, San Diego, California, USA

\section{Correspondence to} Marielle C Brinkman, College of Public Health, The Ohio State University, Columbus, $\mathrm{OH}$ 43210, USA;

brinkman.224@osu.edu

Received 22 January 2019

Revised 10 June 2019

Accepted 13 June 2019

Published Online First

21 September 2019

\begin{abstract}
Objectives We examined mainstream total particulate matter, nicotine, cotinine, menthol, pyrene, carbon monoxide (CO) and semivolatile furan yields from a commercial waterpipe with two methods for heating the tobacco, quick-light charcoal (charcoal) and electric head (electric) and two water bowl preparations: with (ice) and without ice (water).
\end{abstract}

Methods Emissions from a single brand of popular waterpipe tobacco $(10 \mathrm{~g})$ were generated using machine smoking according to a two-stage puffing regimen developed from human puffing topography. Tobacco and charcoal consumption were calculated for each machine smoking session as mass lost, expressed as a fraction of presmoking mass.

Results The heating method had the greatest effect on toxicant yields. Electric heating resulted in increases in the fraction of tobacco consumed (2.4 times more, $p<0.0001)$, mainstream nicotine (1.4 times higher, $p=0.002)$ and semivolatile furan yields (1.4 times higher, $\mathrm{p}<0.03)$, and a decrease in mainstream $\mathrm{CO}$ and pyrene yields (8.2 and 2.1 times lower, respectively, $p<0.001$ ) as compared with charcoal. Adding ice to the bowl resulted in higher furan yields for electric heating. Menthol yields were not different across the four conditions and averaged $0.16 \pm 0.03 \mathrm{mg} / \mathrm{session}$. 2-Furaldehyde and 5-(hydroxymethyl)-2-furaldehyde yields were up to 230 and 3900 times higher, respectively, than those reported for cigarettes.

Conclusion Waterpipe components used to heat the tobacco and water bowl preparation can significantly affect mainstream toxicant yields. Mainstream waterpipe tobacco smoke is a significant source of inhalation exposure to semivolatile furans with human carcinogenic and mutagenic potential. These data highlight the need for acute and chronic inhalation toxicity data for semivolatile furans and provide support for the establishment of limits governing sugar additives in waterpipe tobacco and educational campaigns linking waterpipe tobacco smoking behaviours with their associated harm.

\section{INTRODUCTION}

Waterpipe tobacco smoking (WTS) is an emerging global health risk behaviour, particularly among youth and young adults in several countries, including the USA. ${ }^{1-6}$ Nationally representative US data (2011-2015) showed that WTS' current use (past 30 days) among middle and high-school adolescents ranged from $14.4 \%$ to $35.9 \%$ and among young adults, ages $18-34$ years, ranged from $8.4 \%$ to $15.2 \%$. $^{7}$ WTS has been associated with increased risk for lung, oral, oesophageal and head and neck cancers, and cardiovascular and pulmonary disease. ${ }^{8-11}$ Ever use of waterpipe by those who do not smoke cigarettes was independently associated with twice the odds of initiating cigarette smoking, as reported 1 year later. ${ }^{12}$

A variety of commercial components related to WTS, such as charcoal or electric devices used to heat the tobacco, and ice buckets and ice hose tips to make the smoke smoother, are available. In the USA, waterpipe components are considered tobacco products and subject to Food and Drug Administration (FDA) regulations if they are reasonably expected to (1) alter or affect a tobacco product's performance, composition, constituents or characteristics, and (2) be used with or for the human consumption of a tobacco product. ${ }^{13}$ To determine how waterpipe components affect emissions, waterpipes can be machine smoked according to a human-derived puffing regimen, and the particulate and gas phases can be analysed. Although machine smoking cannot be used to predict human exposures or risk, it can provide useful information regarding the toxicants associated with a given component.

WTS is widely mistakenly perceived as less harmful than other forms of tobacco smoking and sometimes is not even considered smoking. ${ }^{14} 15$ Our unpublished data indicate that some smokers minimise the harshness of tobacco smoke by adding ice to the waterpipe bowl to cool the smoke and soothe the throat during puffing. It is not known whether this practice affects the mainstream smoke emissions.

In 2012, the FDA established a list of harmful and potentially harmful constituents (HPHCs) in tobacco products and smoke. ${ }^{16}$ Manufacturers must provide product listings and report ingredients and HPHCs to the FDA. These data can play an important role in FDA's determination of the regulations needed to protect public health, including setting product standards, such as threshold concentrations of HPHCs that cannot be exceeded. The HPHC list was developed after reviewing disease associated with smoking cigarettes and using smokeless tobacco, as those products fell under FDA's regulatory authority at that time. Four years later, FDA extended their regulatory authorities to more novel tobacco products, including waterpipe tobacco and components. ${ }^{13} 17$ Because of the types and amounts of chemicals that manufacturers add to waterpipe tobacco and the complexity of the various components that may be used to heat the tobacco, WTS may have some unique and/or more abundant toxicant exposures that are not represented in the current HPHC list. The WHO has a similar list of priority toxicants, and both organisations intend 
to periodically revise the list apace with the discovery of scientific information regarding the harm of tobacco product use. ${ }^{16} 18$ In fact, shortly after this work was accepted for publication, the FDA published a proposed update to the HPHC list that included 2-furaldehyde (or furfural), one of the semi-volatile furans we measured. ${ }^{19}$

Semivolatile furans, including furfuryl alcohol (FFA), 2-furaldehyde (2F), and 5-hydroxymethylfurfural (HMF), are more abundant in mainstream waterpipe smoke than cigarette smoke. ${ }^{20}$ There are few data available regarding the toxicological implications of acute and chronic human inhalation of these compounds. In long-term inhalation studies, FFA showed carcinogenic activity in the noses of male rats and the kidneys (renal tubules) of male mice. ${ }^{21} \mathrm{FFA}$ is classified as an International Agency for Research on Cancer (IARC) Class 2 B carcinogen. ${ }^{22}$ Furfural (2F) shows carcinogenicity in experimental animals via oral administration but is classified as an IARC Class 3 carcinogen due to the inadequacy of human evidence. ${ }^{23}$ Concerningly, humans can metabolise both HMF and FFA to form genotoxic and mutagenic compounds (5-sulfoxymethyfurfural ${ }^{24}$ and furfural sulfate, ${ }^{25}$ respectively) in the body via sulfotransferase enzymatic activity. ${ }^{26}$ For this reason, WHO has recommended HMF be given high priority for carcinogenic evaluation. ${ }^{27}$

To contribute to the body of evidence surrounding waterpipe components and emissions, we measured mainstream total particulate matter (TPM), nicotine, cotinine, menthol, benzo(a)pyrene, pyrene, tobacco-specific nitrosamines (TSNAs), carbon monoxide (CO) and semivolatile furan yields in waterpipe tobacco smoke; these data were generated by machine smoking a commercial waterpipe according to a human-derived puffing regimen. We tested two components for heating the tobacco, quick-light charcoal (charcoal) and electric head (electric) and two water bowl preparations: with ice (ice) and without ice (water).

\section{METHODS}

\section{Waterpipe configurations}

A commercial waterpipe (Hookah Egyptian Safari Shisha 22-inch, Khalil Mamoon, Amazon, USA) was equipped as follows to produce four different configurations:

1. Charcoal-water (CW): Perforated aluminium foil (Zebra Smoke, Amazon, USA) was placed over the Egyptian-style ceramic head between the lit charcoal (40 mm, Three Kings, Holland) and the tobacco (Exotic Double Apple, Starbuzz Tobacco, California, USA). The bowl was filled $(470 \mathrm{~mL})$ with bottled water (Water configuration, Nestlé Pure Life, Nestlé Waters North America, Connecticut, USA).

2. Charcoal-ice (CI): same head, foil, charcoal and tobacco as CW, but bowl was partially filled $(293 \mathrm{~mL})$ with bottled water and 15 ice cubes, prepared using the same water.

3. Electric-water (EW): same foil, tobacco and water as CW; the ceramic head had a heating element embedded in the bottom, controlled by a variable power supply with numerical settings, 1-9, where the lowest setting was a dial position below ' 1 ', and the highest setting was a dial position above '9'(see figure 1A, Hookah-Shisha Heater, Ren Headstream, China).

4. Electric-ice (EI): same foil, tobacco and head as EW; bowl was prepared the same as CI.

Four waterpipe sets (clay heads, bowls, stems) were labelled and used in replicate smoking sessions. One electric head was used for all electric smoking sessions. The bottom of the metal stem of the waterpipe was covered with $3.8 \mathrm{~cm}$ of water for all configurations.
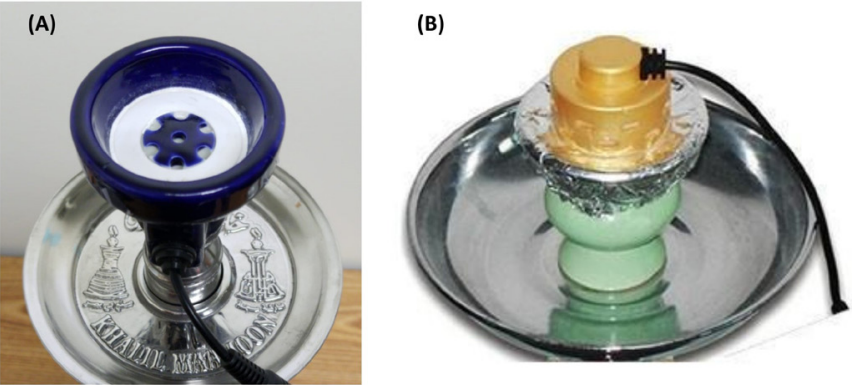

Figure 1 Two commercial components for electrically heating waterpipe tobacco: (A) ceramic heating element located inside the head, positioned underneath the foil and tobacco (this study) and (B) ceramic heating element located on the bottom and positioned above the foil and tobacco in the head.

\section{Machine smoking and mainstream smoke yields}

Stems and rocks were removed from three packages (250 g each) of a popular waterpipe tobacco purchased from one hookah supply store in Columbus, Ohio, May 2018. Tobacco was homogenised by mixing with gloved hands, stored at $6^{\circ} \mathrm{C}$ and brought to room temperature before machine smoking. For machine smoking, the tobacco $(10.0 \pm 0.05 \mathrm{~g})$ was lightly packed in the head, covered with perforated foil and heated. A disposable plastic hose (length of hose $=127 \mathrm{~cm}$; Fancy Hose, Zebra Smoke, Amazon, USA) was connected to the waterpipe, and platinum cured silicone tubing was used to connect the mouth-end of the hose to the smoking machine. For the CW and CI configurations, a single charcoal was placed on top of the foil-covered tobacco after sitting on an electric heater for $100 \mathrm{~s}$. For the EW and EI configurations, the electric head was lined with perforated foil, and larger holes were poked through the foil into the holes in the bottom of the head. Ten grams of tobacco were lightly packed in the head and covered with perforated foil and heated for 3 min prior to the start of each smoking session. The thumbwheel on the power supply was set at ' 3 '; details regarding this setting are presented in the online supplementary methods section. For each session, a smoking machine (modified Hawktech FP2000) was programmed with a two-stage puffing regimen, shown in online supplementary table $\mathrm{S}-1$, derived previously from human waterpipe smoking behaviour. ${ }^{28} 29$ Stage one includes more intense puffing (greater volume, longer duration puffs) for the first $11.2 \mathrm{~min}$ (32 puffs, $4.6 \mathrm{~s}$ duration, 16.4 $\mathrm{s}$ interval), followed by less intense and less frequent puffing in the remaining $22.6 \mathrm{~min}$ (42 puffs, $3.6 \mathrm{~s}$ duration, $28.7 \mathrm{~s}$ interval). Before each session, the puff volume drawn through the waterpipe by the smoking machine was calibrated to within 97\%-103\% of the true value $(720 \mathrm{~mL}$ and $455 \mathrm{~mL})$. Tobacco and charcoal were weighed before and after machine smoking, and consumption was calculated as postweight subtracted from preweight expressed as a fraction of preweight.

As shown in online supplementary figure S-1, samples were generated in 24 machine smoking sessions corresponding to the collection of wet TPM for subsequent extraction and analysis of the particle phase $(n=12$ sessions, 3 replicates per waterpipe configuration) and analysis of $\mathrm{CO}$ in the gas phase $(n=12$ sessions, 3 replicates per waterpipe configuration). TPM for semivolatiles analysis was collected on two parallel filters (92 $\mathrm{mm}$ in diameter, Cambridge, Hamburg, Germany) located at the mouth-end of the waterpipe hose. Filters were recovered immediately after smoking, and the mass of wet TPM was determined gravimetrically. Filters were placed in their cleaned extraction vessels and stored at $-20^{\circ} \mathrm{C}$ prior to extraction. One filter was 
Table 1 Consumption and mainstream yields; data presented are mean (SD) of $n=3$ smoking sessions unless otherwise stated

\begin{tabular}{|c|c|c|c|c|c|c|c|c|c|}
\hline \multirow{3}{*}{$\begin{array}{l}\text { Consumption/Emissions per } \\
\text { smoking session }\end{array}$} & \multirow{3}{*}{$\begin{array}{l}\text { Units/ } \\
\text { Session }\end{array}$} & \multirow[b]{3}{*}{ CW } & \multirow[b]{3}{*}{ EW } & \multirow[b]{3}{*}{$\mathrm{Cl}$} & \multirow[b]{3}{*}{ EI } & \multicolumn{4}{|l|}{$P$ value } \\
\hline & & & & & & \multicolumn{2}{|c|}{ Charcoal versus electric } & \multicolumn{2}{|c|}{ Water versus ice } \\
\hline & & & & & & CW:EW & Cl:EI & CW:Cl & EW:EI \\
\hline \multicolumn{10}{|c|}{ Tobacco and charcoal consumption } \\
\hline Tobacco consumed & $\%$ & $28.5(2.05)$ & $70.6(3.71)$ & $26.6(4.40)$ & $73.1(2.07)$ & $<0.001$ & $<0.001$ & 0.529 & 0.367 \\
\hline Charcoal consumed, $n=9$ & $\%$ & $66.3(2.81)$ & & $67.4(2.44)$ & & & & 0.383 & \\
\hline \multicolumn{10}{|l|}{ TPM, N, CO, and PAH } \\
\hline Total particulate matter & g & $1.08(0.250)$ & $0.880(0.059)$ & $0.583(0.102)$ & $0.703(0.061)$ & 0.115 & 0.330 & 0.003 & 0.164 \\
\hline Nicotine & $\mathrm{mg}$ & $0.653(0.173)$ & $0.848(0.015)$ & $0.550(0.086)$ & $0.805(0.027)$ & 0.040 & 0.013 & 0.233 & 0.601 \\
\hline $\mathrm{CO}$ & $\mathrm{mg}$ & $97.4(0.261)$ & $12.7(2.88)$ & $109(11.7)$ & $12.5(1.34)$ & $<0.001$ & $<0.001$ & 0.053 & 0.968 \\
\hline Menthol & $\mathrm{mg}$ & $0.144(0.033)$ & $0.140(0.008)$ & $0.187(0.037)$ & $0.187(0.008)$ & 0.851 & 0.987 & 0.070 & 0.051 \\
\hline Cotinine & $\mu \mathrm{g}$ & $0.586(0.180)$ & $1.09(0.095)$ & $0.594(0.192)$ & $0.910(0.374)$ & 0.004 & $<0.001$ & 0.953 & 0.054 \\
\hline Pyrene & $\mathrm{ng}$ & $190(32.7)$ & $91.7(14.2)$ & $192(31.2)$ & $90.0(14.7)$ & 0.001 & 0.001 & 0.924 & 0.936 \\
\hline \multicolumn{10}{|l|}{ Furans } \\
\hline HMF & $\mu \mathrm{g}$ & $3690(1010)$ & $5050(148)$ & $3200(660)$ & $4660(265)$ & 0.028 & 0.021 & 0.363 & 0.464 \\
\hline FFA & $\mu \mathrm{g}$ & $218(75.0)$ & $289(24.0)$ & $313(67.2)$ & 491 (12.9) & 0.134 & 0.003 & 0.055 & 0.001 \\
\hline 2-FA & $\mu \mathrm{g}$ & $101(32.8)$ & $179(18.5)$ & 84.7 (13.2) & $171(8.56)$ & 0.002 & 0.001 & 0.363 & 0.629 \\
\hline $2 \mathrm{~F}$ & $\mu \mathrm{g}$ & $62.0(17.8)$ & $149(58.2)$ & $60.8(16.9)$ & $163(15.7)$ & 0.012 & 0.005 & 0.965 & 0.592 \\
\hline 2-FMK & $\mu \mathrm{g}$ & $5.91(2.14)$ & $17.4(2.52)$ & $5.94(1.27)$ & $27.3(1.16)$ & $<0.001$ & $<0.001$ & 0.985 & $<0.001$ \\
\hline $5 \mathrm{M}-2-\mathrm{F}$ & $\mu \mathrm{g}$ & 36.1 (13.8) & $113(24.1)$ & $41.0(10.5)$ & $142(3.32)$ & $<0.001$ & $<0.001$ & 0.696 & 0.044 \\
\hline
\end{tabular}

Bold font shows mean differences that are significant at $\mathrm{p}<0.05$ level.

$\mathrm{Cl}$, charcoal with ice; $\mathrm{CO}$, carbon monoxide; CW, charcoal with water; El, electric with ice; EW, electric with water; 2F, furfural; FFA, furfuryl alcohol; HMF, 5-Hydroxymethylfurfural; $\mathrm{N}$, nicotine; PAH, polycyclic aromatic hydrocarbon; TPM, total particulate matter.

chemically extracted and analysed for target semivolatile organic compounds using gas chromatography mass spectrometry and TSNAs using liquid chromatography with tandem mass spectrometry. The other filter was extracted and analysed for furans using reverse-phase high performance liquid chromatography with diode array detection. A final set of 12 machine smoking sessions was conducted for the quantification of $\mathrm{CO}$.

Menthol, nicotine, cotinine, benzo(a)pyrene (BaP), pyrene, $\mathrm{N}^{\prime}$-nitrosonornicotine (NNN), 4-(methylnitrosamino)-1(3-pyridyl)-1-butanone (NNK) and nine semivolatile furans (see online supplementary figure S-1 and table S-2) were quantified in the wet TPM, and CO was quantified in the gas phase; methodological details can be found in the online supplementary methods section.

\section{RESULTS}

\section{Consumption and mainstream yields}

Table 1 shows average consumption and mainstream yields for the four waterpipe configurations. Overall, the heating source had a bigger impact on mainstream yields than ice added to the water bowl. The electric head resulted in 2.4 times more tobacco being consumed per session $(\mathrm{p}<0.001)$ and $1.3-1.5$ times higher nicotine ( $\mathrm{ps}<0.041), 1.5-1.9$ higher cotinine $(\mathrm{ps}<0.005)$ and 1.3-4.6 times higher furan yields (ps<0.029) as compared with charcoal. Electric heating resulted in 7.7-8.7 times lower yields of CO (ps<0.001) and 2.1 times lower yields of pyrene (ps< $<002)$ as compared with charcoal. There was no difference in mainstream TPM between electric and charcoal heating. Adding ice resulted in small increases (1.3-1.7X more) in some furan yields for electric heating $(\mathrm{ps}<0.045)$ and a minor reduction $(1.2 \mathrm{X}$ less $)$ in TPM yield $(\mathrm{p}<0.003)$ for charcoal heating, although the wide variability of the TPM data for charcoal heating is concerning. There was no difference in menthol emissions across the four configurations. 3-FM, 3F and MF were not detected in the smoke from any configuration. NNN, NNK and $\mathrm{BaP}$ were also not detected, which is surprising given previous reports of up to $34 \mathrm{ng} /$ session for NNN, $46 \mathrm{ng} /$ session for NNK and $307 \mathrm{ng} /$ session for $\mathrm{BaP}^{30}$ Our shorter smoking session (33 vs $60 \mathrm{~min}$ ) and splitting the sample in quarters, once during TPM collection onto two filters and once during chemical extraction when splitting the extract in half, resulted in less sensitive methodology. Table 2 shows the chemical yields measured for mainstream waterpipe versus extant yields reported for filtered cigarette smoke. Waterpipe yields were significantly higher than those reported for cigarettes for all compounds measured except nicotine, menthol and cotinine.

Table 2 Range reported in the literature for filtered cigarettes and this study's waterpipe mainstream smoke yields for a single brand

\begin{tabular}{|c|c|c|c|}
\hline Target compound & CAS number & $\begin{array}{l}\text { Filtered cigarette } \\
\text { (mass per rod)* }\end{array}$ & $\begin{array}{l}\text { Waterpipe } \\
\text { (mass per } \\
\text { session)t }\end{array}$ \\
\hline $\begin{array}{l}\text { Total particulate } \\
\text { matter, mg }\end{array}$ & - & $4.5-45$ & $583-1080$ \\
\hline Nicotine, mg & $54-11-5$ & $0.19-3.69$ & $0.55-0.85$ \\
\hline $\mathrm{CO}, \mathrm{mg}$ & $630-08-0$ & $1.21-31.5$ & $12.5-97.4$ \\
\hline Menthol, mg & $2216-51-5$ & $0-3.92 \ddagger$ & $0.14-0.19$ \\
\hline Cotinine, $\mu \mathrm{g}$ & $486-56-6$ & $2.66-4.05$ & $0.59-1.09$ \\
\hline Pyrene, ng & $129-00-0$ & $49.5 \S$ & 90-192 \\
\hline $\mathrm{HMF} \mu \mathrm{g}$ & $67-47-0$ & 1.3-7.4ๆ & $3200-5050$ \\
\hline $\mathrm{FFA}, \mu \mathrm{g}$ & $98-00-0$ & $18-65$ & 218-491 \\
\hline $2-F A, \mu g$ & $88-14-2$ & $44-107$ & $84.7-179$ \\
\hline $2 \mathrm{~F}_{,} \mu \mathrm{g}$ & 98-01-1 & $0.71-27.5$ & $60.8-163$ \\
\hline 2-FMK, $\mu \mathrm{g}$ & $1192-62-7$ & $0.54^{* *}$ & $5.91-27.3$ \\
\hline $5 \mathrm{M}-2-\mathrm{F}, \mu \mathrm{g}$ & $620-02-0$ & $6-29$ & $36.1-142$ \\
\hline
\end{tabular}

${ }^{*}$ Yields from from reference ${ }^{61}$. Note: Tar yields shown for total particulate matter. †Yields from single brand of tobacco examined in this study.

‡Data estimated from rod contents reported in reference ${ }^{56}$; assumed $20 \%$ transfer to smoke.

§Yields reported for $1 \mathrm{R} 4 \mathrm{~F}$ and $2 \mathrm{R} 4 \mathrm{~F}$ in reference ${ }^{62}$

ๆYields from filtered cigarettes measured in reference ${ }^{63}$ :

${ }^{* *}$ Yield taken from $0 \%$ potassium lactate cigarette reported in reference ${ }^{64}$. 


\section{Component temperature}

Temperature of the electric head ranged from $300^{\circ} \mathrm{C}$ to $380^{\circ} \mathrm{C}$, depending on the power supply setting (see online supplementary figure S-2). Maximum tobacco temperature obtained when using electric heating $\left(\sim 300^{\circ} \mathrm{C}\right)$ was almost twice that obtained when using charcoal heating $\left(\sim 150^{\circ} \mathrm{C}\right)$, as shown in online supplementary figures S-3 and S-4. The electric head's power supply setting had little effect on the average tobacco temperature.

\section{DISCUSSION}

The study results have several policy and regulatory implications regarding waterpipe components, tobacco additives and consumer education.

\section{Waterpipe components and toxicant yields}

Both heating sources affected the mainstream smoke yields, and thus we recommend these components be regulated as tobacco products. However, a categorical statement about the harm of electric heating cannot reasonably be made, because previously we found that an electric heater (same manufacturer) designed to sit on top of the foil-covered tobacco, as shown in figure $1 \mathrm{~B}$, gave much lower nicotine yields compared with charcoal heating. ${ }^{29}$ The heaters themselves achieve the same maximum temperature, but the temperature in the tobacco and corresponding nicotine yields were more than twice as high compared with charcoal heating when using the electric heater examined in this study. This is likely because thermal energy is more efficiently conducted to the tobacco when using the electric head because the surface area that gets hot $\left(45.6 \mathrm{~cm}^{2}\right)$ is seven times greater than that of the top heater examined previously $\left(6.2 \mathrm{~cm}^{2}\right)$. As the tobacco heats up, so does the vapour concentration of nicotine and cotinine in the head, due to their increasing volatility/vapour pressure. ${ }^{3132}$ The temperature of the tobacco (not necessarily the heater) drives the mainstream toxicant emission rates, and the physical design of the heating component can determine the tobacco temperature. Since these data were generated using a smoking machine, it is not known whether the increased nicotine and toxicant delivery from the electric heater studied here (figure 1A) will result in changes in human puffing behaviour and biomarkers of waterpipe smoke exposure as compared with charcoal heating. The human component of this project, not reported here, will determine the differential effects of waterpipe smoking practices on biomarkers of toxicity. There is some evidence that reduced nicotine yield in waterpipe $(78 \%$ reduction) is associated with increased human exposure to toxicants because of puffing compensation. ${ }^{29}$ Given the direct relationship between tobacco temperature and some toxicant emissions, further evidence to inform a product standard, such as setting a threshold for the maximum tobacco temperature achievable by electric heaters, is needed.

\section{Indirect and direct harm from waterpipe tobacco additives}

Mainstream waterpipe tobacco smoke yields measured here for FFA, 2F and HMF were substantially higher than cigarette yields reported in the literature for these same compounds $(>12,85$ and 2500 times higher, respectively), and thus we recommend more extensive study of the toxicity of these compounds. Although we only tested one tobacco, Schubert et al, ${ }^{20}$ reported similarly high levels for five other brands of waterpipe tobacco. The uniquely high semivolatile furan emissions make these chemicals distinctive exposures for this tobacco product type (waterpipe), as defined by Klupinski et $a l^{33}$; and more testing is needed to understand their impact on public health.
Table 3 SPI derived from extant literature for tobacco filler of combustible tobacco product types

\begin{tabular}{llll}
\hline Tobacco product type & SPI & Nicotine $(\mathrm{mg} / \mathrm{g})$ & Sugars $(\mathrm{mg} / \mathrm{g})$ \\
\hline Waterpipe (Ma'assel) & 290 & $1.2^{*}$ & $350 \dagger$ \\
Pipe & $1.6-13$ & $14.4 \ddagger$ & $24-189 \S$ \\
Cigarettes & $0.4-9.5$ & $19 \uparrow$ & $7-180 \S$ \\
Cigars & $0.4-0.5$ & $15 ף$ & $6-7.5 \S$ \\
\hline
\end{tabular}

*Kulak et al, $2017^{65}$

†Brinkman et al, $2018^{35}$

$\ddagger$ Jacob et al, $1999^{66}$

§Elson et al, $1972^{34}$

qLawler et al, 2017 67

SPI, Starter Product Index.

The high concentrations of these furans are likely due to the fate of the sweet additives in the tobacco. Sugars like fructose, glucose and sucrose are formed during tobacco harvesting and curing at total levels of up to $\sim 200 \mathrm{mg} / \mathrm{g}$ in cigarette tobacco. ${ }^{34}$ However, sweetened waterpipe tobacco, or ma'assel, has much higher concentrations of these sweet chemicals, as much as 60 times higher, ${ }^{34-36}$ indicating the tobacco is heavily fortified with these chemicals during manufacturing.

Sugar additives may increase the appeal of the smoke, making it easier for users to start smoking/initiate inhalation of nicotine. The tobacco industry adds these same sugars to cigarette tobacco to impart 'smoothness' to the mainstream smoke and has conducted human studies to determine the optimal ratio of added sugar to nicotine. ${ }^{37}$ To emphasize the unique chemistry of waterpipe tobacco and how it may play an important role in smoking initiation, we define a similar term, Starter Product Index (SPI), as the mass of simple sugars divided by the mass of nicotine in the tobacco. Data for tobacco from four combustible product types, waterpipe, pipe, cigarettes and cigars were gleaned from the literature, the SPI was calculated, and results are summarised in table 3. Waterpipe tobacco has an SPI of 290, which is 14-725 times higher than any of the other combustible product types shown in table 3. This ratio makes waterpipe an 'ideal' nicotine starter product for youth, because sweet flavours mask the unpleasant bitter taste of nicotine ${ }^{38}$ and can play a powerful role in tobacco product initiation. ${ }^{39}$ Because these additives can transfer to the smoke, ${ }^{40} 41$ they can simultaneously facilitate the transfer ${ }^{35}$ and addictiveness ${ }^{36}$ of nicotine while reducing the harshness and increasing the appeal of tobacco smoke. ${ }^{2042}$

Sweet additives can also increase the toxicity of the smoke by chemically transforming to carcinogens and respiratory irritants when heated. ${ }^{36}$ There is a common belief that waterpipe tobacco, or ma'assel, is sweetened by adding honey, perhaps because 'ma'assel' is taken from the Arabic 'muassel', which means 'honeyed'. ${ }^{43}$ Given the low cost of waterpipe tobacco (as compared with cigarettes), and that the worldwide market for it exceeded $\$ 1.9 \mathrm{~B}$ in $2017,{ }^{44}$ it is likely that adulterated honey, or so-called 'funny honey', that has been diluted with less expensive syrups is used. ${ }^{45}$ Manufacturers add cheaper chemicals that are perceived as sweet, such as glycerin and molasses, and some state this practice on their websites (see online supplementary figure S-5). Beet and sugar cane molasses are inexpensive by-products of the sugar industry and are readily available at low cost. ${ }^{46}$ Half the weight of molasses is comprised of sugars, including sucrose (34\%), fructose $(8 \%)$ and glucose $(7 \%) .{ }^{47}$ Another inexpensive, readily available sweet additive that is potentially responsible for the high furan emissions is high-fructose corn syrup (HFCS). HFCS is widely used as a sweetener in the processed food and beverage industry and can degrade during storage to 
form $\mathrm{HMF}^{48}$ The mainstream HMF levels measured here are over four orders of magnitude higher than those reported for cigarettes (table 2). Given HMF's presence at milligram levels in mainstream waterpipe smoke, and this compound's potential to form genotoxic metabolites in the lung, ${ }^{24}$ further study is needed to inform product standards such as setting maximum thresholds for added sugars in waterpipe tobacco.

Honey, molasses and HFCS all contain simple sugars, whose molecules contain six carbon atoms, called hexoses. Hexoses can be chemically transformed via thermal dehydration into HMF. ${ }^{49}$ Similarly, pentoses such as raffinose (also found in molasses at $1.3 \%-3.8 \%)^{50}$ can be thermally dehydrated into $2 \mathrm{~F}$.

Another chemical that reduces the harshness of smoke, menthol, has also been linked to facilitating tobacco initiation in youth ${ }^{51}$ and increased difficulty in successfully quitting cigarette smoking. ${ }^{5253}$ Government legislators are beginning to acknowledge menthol's power to contribute to the 2 trillion dollar (purchasing power parity) economic cost to society each year from tobacco use ${ }^{54}$ : Brazil, Ethiopia, the European Union, Turkey and five Canadian provinces have banned the sale of menthol in tobacco products, ${ }^{54}$ and recently the US FDA announced it will be taking similar steps with proposed rulemaking. ${ }^{55}$ It is not known whether the menthol levels measured here are generalisable to waterpipe tobaccos that do not specify words like 'mint' or 'ice' on the label. Similar to what has been done for cigarettes, ${ }^{56}$ future work should include characterising menthol levels for mentholated and non-mentholated waterpipe tobaccos.

\section{Waterpipe smoking practices and toxicant yields}

The practice of adding ice to the bowl resulted in direct harm in the form of minor increases to yields for some target furans when smoking at the higher temperatures achieved by the electric heater. Because of the greater variability associated with charcoal heating, the reduction in TPM when smoking with ice in the bowl requires replication. Human research is needed to understand the potential harm from this practice and how best to educate the public regarding the association between increased appeal and exposure to toxicants, and tobacco smoke/nicotine initiation and addiction.

\section{Limitations}

The data reported here have limitations. Machine smoking yield data must not be confused with valid measures of human exposure or risk. ${ }^{5758}$ These data were generated using one brand of commercial waterpipe, hose, electric head and tobacco and may not be generalised for the variety of commercial waterpipes and tobaccos sold worldwide. Our study focused primarily on toxicants in the particle phase plus $\mathrm{CO}$; future work should examine volatile toxicants in the gas phase such as 1,3-butadiene, acetaldehyde, acrolein, benzene and furan.

\section{CONCLUSION}

Public health issues surrounding waterpipe, which include distinctive toxicants generated and mediated by the tobacco and waterpipe components, are very different from cigarette use. ${ }^{59}$ We measured mainstream TPM, nicotine, cotinine, menthol, pyrene, $\mathrm{CO}$ and semivolatile furan yields from smoking a commercial tobacco and waterpipe equipped with two different components and two different water bowl preparations. Differences in nicotine yields and high concentrations of potentially carcinogenic and mutagenic furans indicate more research is needed to understand the interplay between heating components, tobacco temperature and sugar additives, smoke toxicity and tobacco product initiation, addiction potential and toxicity. To better understand waterpipe tobacco smoking behaviours, questions regarding the prevalence of use of specific components such as electric heaters and practices such as adding ice to the bowl should be included in future smoker surveillance. Smoker's behaviours can also reduce the harshness of waterpipe smoke, increasing the potential for indirect harm. Because these personal waterpipe smoking behaviours cannot be regulated, educational campaigns and other prevention strategies are needed for this unique form of tobacco use. ${ }^{60}$

\section{What this paper adds}

Our results have regulatory implications in that they:

- Demonstrate that waterpipe components such as charcoal or electric heads can alter and affect the toxicity of mainstream waterpipe tobacco smoke.

- Confirm that semivolatile furans with human carcinogenic and mutagenic potential are present in waterpipe smoke at significantly higher levels than cigarette smoke and highlight the need for greater understanding of the toxicity associated with acute and chronic inhalation exposure to these chemicals.

- Provide a theoretical rationale for the need to regulate the amount of added sugars in waterpipe tobacco.

- Support the need for educational campaigns surrounding user behaviours and the harm from waterpipe tobacco smoking.

Correction notice Please note that this article as been updated since it was published Online First. A typo in the Results section of the Abstract was corrected and the Acknowledgements section was expanded to include all of the Battelle study team members and their roles on the project.

Acknowledgements Battelle Memorial Institute was responsible for conducting all the mainstream smoke sample generation and chemical constituent analyses. The authors would like to thank the following individuals: Anna Adetona (Technical lead for overall project implementation of the laboratory work, which included temperature assessments, gravimetric results, $\mathrm{CO}$ analysis, furan methods development, machine smoking and sample generation, compilation and evaluation of the data), Stephanie Buehler (Task lead for TSNA and SVOCs analyses, furan methods development, compilation and evaluation of the data), Alex Ivanov, Clint Fleshman, Ben Engelhardt, and Kandice Cross (Laboratory staff for conducting all machine smoking, $\mathrm{CO}$ analysis, and sample generation), Larry Mullins and Kristara Abrams (Task lead and chemist for furan methods development and chemical analysis), Christina Saeger (Chemist for TSNA analysis), and Quintella Bester (Project manager).

Contributors MCB, NOK and NOFK were responsible for the conception and design of the study. AAT was responsible for the statistical analysis. All authors contributed to the analysis and interpretation of the data and the preparation of the manuscript.

Funding Research reported in this publication was supported by the National Institute on Drug Abuse of the National Institutes of Health under Award Number R01DA042471 to NOFK. Battelle Memorial Institute, contracted by San Diego State University, conducted all the machine smoking and associated chemical constituent analyses including method development for furans evaluated under this grant.

Disclaimer The content is solely the responsibility of the authors and does not necessarily represent the official views of the National Institutes of Health.

Competing interests MCB is currently employed by The Ohio State University. MCB worked in conjunction with NOFK (the Principal Investigator) on the study design while employed at Battelle.

Patient consent for publication Not required.

Provenance and peer review Not commissioned; externally peer reviewed.

Data availability statement Data are available upon reasonable request. All data relevant to the study are included in the article or uploaded as supplementary information.

ORCID iD

Marielle C Brinkman http://orcid.org/0000-0002-4315-649X 


\section{REFERENCES}

1. Maziak W, Taleb ZB, Bahelah R, et al. The global epidemiology of waterpipe smoking. Tob Control 2015;24 Suppl 1:i3-12.

2. Jawad M, Charide R, Waziry $R$, et al. The prevalence and trends of waterpipe tobacco smoking: a systematic review. PLoS One 2018;13:e0192191.

3. Morton J, Song $Y$, Fouad $\mathrm{H}$, et al. Cross-country comparison of waterpipe use: nationally representative data from 13 low and middle-income countries from the global adult tobacco Survey (GATS). Tob Control 2014;23:419-27.

4. Agaku IT, Filippidis FT, Vardavas $\mathrm{Cl}$, et al. Poly-tobacco use among adults in 44 countries during 2008-2012: evidence for an integrative and comprehensive approach in tobacco control. Drug Alcohol Depend 2014;139:60-70.

5. Jawad M, Lee JT, Millett C. Waterpipe tobacco smoking prevalence and correlates in 25 Eastern Mediterranean and Eastern European countries: cross-sectional analysis of the global youth tobacco survey. Nicotine Tob Res 2016;18:395-402.

6. Kasza KA, Ambrose BK, Conway KP, et al. Tobacco-Product use by adults and youths in the United States in 2013 and 2014. N Eng/ J Med 2017;376:342-53.

7. Johnson AL, Collins LK, Villanti AC, et al. Patterns of nicotine and tobacco product use in youth and young adults in the United States, 2011-2015. Nicotine Tob Res 2018;20(suppl_1):S48-S54.

8. Mamtani R, Cheema S, Sheikh J, et al. Cancer risk in waterpipe smokers: a metaanalysis. Int J Public Health 2017;62:73-83.

9. Waziry R, Jawad M, Ballout RA, et al. The effects of waterpipe tobacco smoking on health outcomes: an updated systematic review and meta-analysis. Int J Epidemiol 2017;46:32-43.

10. El-Zaatari ZM, Chami HA, Zaatari GS. Health effects associated with waterpipe smoking. Tob Control 2015;24 Suppl 1:i31-43.

11. Rezk-Hanna M, Benowitz NL. Cardiovascular effects of hookah smoking: potential implications for cardiovascular risk. Nicotine Tob Res 2018:1-11.

12. Watkins SL, Glantz SA, Chaffee BW. Association of noncigarette tobacco product use with future cigarette smoking among youth in the population assessment of tobacco and Health (path) study, 2013-2015. JAMA Pediatr 2018;172:181-7.

13. Food and Drug Administration, HHS. Deeming tobacco products to be subject to the federal food, drug, and cosmetic Act, as amended by the family smoking prevention and tobacco control act; restrictions on the sale and distribution of tobacco products and required warning statements for tobacco products. final rule. Fed Regist 2016;81.

14. Grekin ER, Ayna D. Waterpipe smoking among college students in the United States: a review of the literature. J Am Coll Health 2012;60:244-9.

15. Strong DR, Messer K, White $M$, et al. Youth perception of harm and addictiveness of tobacco products: findings from the population assessment of tobacco and health study (wave 1). Addict Behav 2019;92:128-35.

16. US Food drug administration. Harmful and potentially harmful constituents in tobacco products and tobacco smoke; established list. Fed Regist 2012;77:20034-7.

17. Backinger CL, Meissner HI, Ashley DL. The FDA "Deeming Rule" and Tobacco Regulatory Research. Tob Regul Sci 2016;2:290-3.

18. WHO framework convention on tobacco control, world Health organization, Geneva, Switzerland, 2003. Available: https://www.who.int/tobacco/framework/WHO_FCTC_ english.pdf

19 Food and Drug Administration HHS. Harmful and potentially harmful constituents in tobacco products; established list; proposed additions; Request for comments. Fed Regist 2019;84.

20. Schubert J, Bewersdorff J, Luch A, et al. Waterpipe smoke: a considerable source of human exposure against furanic compounds. Anal Chim Acta 2012;709:105-12.

21. Toxicology and carcinogenesis studies of furfuryl alcohol (Cas No. 98-00-0) in $\mathrm{f344/ \textrm {n }}$ rates and B6C3F1 mice (inhalation studies). February 1999. National Toxicology Program, NTP TR 482, Publ. No. 99-3972. Available: https://ntp.niehs.nih.gov/ntp/ htdocs/lt_rpts/tr482.pdf

22. Some chemicals that cause tumours of the urinary tract in rodents/ IARC Working Group on the Evaluation of Carcinogenic Risks to Humans (2017: Lyon, France) (IARC monographs on the evaluation of carcinogenic risks to humans; volume 119). Available: http://publications.iarc.fr/575

23. IARC monograph, vol. 63, 1995. Available: https://monographs.iarc.fr/wp-content/ uploads/2018/06/mono63-17.pdf

24. Abraham K, Gürtler R, Berg K, et al. Toxicology and risk assessment of 5-hydroxymethylfurfural in food. Mol Nutr Food Res 2011;55:667-78.

25. Glatt $H$, Schneider $H$, Murkovic $M$, et al. Hydroxymethyl-substituted furans: mutagenicity in Salmonella typhimurium strains engineered for expression of various human and rodent sulphotransferases. Mutagenesis 2012;27:41-8.

26. Coughtrie MWH. Function and organization of the human cytosolic sulfotransferase (SULT) family. Chem Biol Interact 2016;259:2-7.

27. IARC Monographs on the evaluation of carcinogenic risks to humans. Lyon, France IARC; 2014. https://monographs.iarc.fr/wp-content/uploads/2018/08/14-002.pdf

28. Brinkman MC, Kim H, Gordon SM, et al. Design and validation of a researchgrade waterpipe equipped with puff topography analyzer. Nicotine Tob Res 2016;18:785-93.

29 Brinkman MC, Kim H, Buehler SS, et al. Evidence of compensation among waterpipe smokers using harm reduction components. Tob Control 2020;29:15-23.
30. Shihadeh A, Schubert J, Klaiany J, et al. Toxicant content, physical properties and biological activity of waterpipe tobacco smoke and its tobacco-free alternatives. Tob Control 2015;24 Suppl 1:i22-30.

31. Harlan WR, Hixon RM. Volatility of nicotine. Indust Eng Chem 1927;20:723-4.

32. Siitsman C, Kamenev I, Oja V. Vapor pressure data of nicotine, anabasine and cotinine using differential scanning calorimetry. Thermochimica Acta 2014;595:35-42.

33. Klupinski TP, Strozier ED, Friedenberg DA, et al. Identification of new and distinctive exposures from little cigars. Chem Res Toxicol 2016;29:162-8.

34. Elson LA, Betts TE, Passey RD. The sugar content and the $\mathrm{pH}$ of the smoke of cigarette, cigar and pipe tobaccos in relation to lung cancer. Int J Cancer 1972;9:666-75.

35. Brinkman MC, Adetona AM, Buehler SS, et al. The effect of Humectant and Flavorant content on harmful and potentially harmful constituent emissions in mainstream waterpipe tobacco smoke. Presented at Symposium 18 at the annual conference of the Society for Research on Nicotine and Tobacco; Feb. 23, 2018, Baltimore, MD, 2018.

36. Talhout R, Opperhuizen A, van Amsterdam JGC. Sugars as tobacco ingredient: effects on mainstream smoke composition. Food Chem Toxicol 2006;44:1789-98.

37. Shelar GR, Bernasek PF, Furin OP. Sugar/Nicotine Study, Report \# ATP 92-210, ATP-R\&D, July 29, 1992. Bates 510697389-510697410.. Available: https://www. industrydocuments.ucsf.edu/docs/fxbl0037

38. Ley JP. Masking bitter taste by molecules. Chemosens Percept 2008;1:58-77.

39. Villanti AC, Johnson AL, Ambrose BK, et al. Flavored tobacco product use in youth and adults: findings from the first wave of the path study (2013-2014). Am J Prev Med 2017;53:139-51.

40. Sepetdjian E, Abdul Halim R, Salman R, et al. Phenolic compounds in particles of mainstream waterpipe smoke. Nicotine Tob Res 2013;15:1107-12.

41. Schubert J, Heinke V, Bewersdorff J, et al. Waterpipe smoking: the role of humectants in the release of toxic carbonyls. Arch Toxicol 2012;86:1309-16.

42. Schubert J, Luch A, Schulz TG. Waterpipe smoking: analysis of the aroma profile of flavored waterpipe tobaccos. Talanta 2013;115:665-74.

43. Khater EM, Amr M, Chaouachi K. Elemental characterization of shisha moasse smoking mixtures using ICP-MS and comparison with other tobacco products. Wulfenia J 2014;21:428-49.

44. Hookah (Shisha) Tobacco Market. 2018 Global Industry Demand, Sales, Suppliers, Analysis \& Forecasts to 2023, 2018. Available: ABNewswire.com

45. Strayer SE, Everstine K, Kennedy S. Economically motivated adulteration of honey: quality control vulnerabilities in the International honey market. Food Prot Trends 2014;34:8-14.

46. Kotzamanidis C, Roukas T, Skaracis G. Optimization of lactic acid production from beet molasses by Lactobacillus delbrueckii NCIMB 8130. World J Microb Biot 2002;18:441-8.

47. Damon CE, Pettitt BC. High performance liquid chromatographic determination of fructose, glucose, and sucrose in molasses. J Assoc Off Ana Chem 1980;63:476-80.

48. LeBlanc BW, Eggleston G, Sammataro D, et al. Formation of hydroxymethylfurfural in domestic high-fructose corn syrup and its toxicity to the honey bee (Apis mellifera). J Agric Food Chem 2009;57:7369-76.

49. Corma A, Iborra S, Velty A. Chemical routes for the transformation of biomass into chemicals. Chem Rev 2007;107:2411-502.

50. Pynnonen B. Analysis of sucrose, raffinose, betaine, and invert in molasses and in the extract and raffinate obtained from ion exclusion. 26thGeneral Meeting American Society of Sugar Beet Technologists; February 25, 1991, Monterey, CA, 1991.

51. D'Silva J, Cohn AM, Johnson AL, et al. Differences in subjective experiences to first use of menthol and Nonmenthol cigarettes in a national sample of young adult cigarette smokers. Nicotine Tob Res 2018;20:1062-8.

52. Stahre M, Okuyemi KS, Joseph AM, et al. Racial/ethnic differences in menthol cigarette smoking, population quit ratios and utilization of evidence-based tobacco cessation treatments. Addiction 2010;105 Suppl 1:75-83.

53. Delnevo CD, Gundersen DA, Hrywna M, et al. Smoking-cessation prevalence among U.S. smokers of menthol versus non-menthol cigarettes. Am J Prev Med 2011;41:357-65.

54. Drope J, Schluger NW, eds. Tobacco Atlas. 6th ed. The American Cancer Society, Inc, 2018.

55. FDA Center for Tobacco Products. FDA unveils new steps to protect youth by preventing access to flavored tobacco products, Announced plans to ban mentho in cigarettes and Cigars, 2018. Available: https://www.fda.gov/TobaccoProducts/ NewsEvents/ucm625992.htm

56. Ai J, Taylor KM, Lisko JG, et al. Menthol content in US marketed cigarettes. Nicotine Tob Res 2016;18:1575-80.

57. World Health Organization. Who tobacco free initiative. Standard operating procedure for intense smoking of cigarettes, 2012. Available: http://apps.who.int/iris/bitstream/ handle/10665/75261/9789241503891_eng.pdf

58. Burns DM, Dybing E, Gray N, et al. Mandated lowering of toxicants in cigarette smoke: a description of the World Health organization TobReg proposal. Tobacco Control 2008;17:132-41.

59. World Health Organization. WHO TobReg: report on the scientific basis of tobacco product regulation: 6th report of a WHO study group 
60. Lopez AA, Eissenberg $T$, Jaafar M, et al. Now is the time to advocate for interventions designed specifically to prevent and control waterpipe tobacco smoking. Addict Behav 2017;66:41-7.

61. Hiranita T, Goodwin AK, Orru M, et al. Yields of various cigarette product constituents in mainstream smoke. SF J Addic Ther 2018;2:1-64.

62. Ding YS, Trommel JS, Yan XJ, et al. Determination of 14 polycyclic aromatic hydrocarbons in mainstream smoke from domestic cigarettes. Environ Sci Technol 2005:39:471-8.

63. Perini FR. 5-Hydroxymethylfurfural (HMf) in selected cigarette brands. Lorillard research center Greensboro. Bates 87519365-87519365S, 1982. Available: https:// www.industrydocuments.ucsf.edu/docs/xmkw0066
64. Yin C, Xu Z, Shu J, et al. Study on the effect of potassium lactate additive on the combustion behavior and mainstream smoke of cigarettes. J Therm Anal Calorim 2014;115:1733-51.

65. Kulak JA, Goniewicz ML, Giovino GA, et al. Nicotine and pH in waterpipe tobacco. Tob Regul Sci 2017;3:102-7.

66. Jacob P, Yu L, Shulgin AT, et al. Minor tobacco alkaloids as biomarkers for tobacco use: comparison of users of cigarettes, smokeless tobacco, cigars, and pipes. Am J Public Health 1999;89:731-6.

67. Lawler TS, Stanfill SB, deCastro BR, et al. Surveillance of nicotine and pH in cigarette and cigar filler. Tob Regul Sci 2017;3(Suppl 1):101-16. 